\title{
A Perceptual-Acoustic Study of the Pragmatic Marker You Know in Egyptian English Spoken Discourse
}

\author{
Tohamy, $M .^{1} \&$ Algamal, $A .^{2}$ \\ ${ }^{1,2}$ Suez Canal University (Faculty of Arts and Humanities, \\ Department of English Language \& Literature) \\ mohamed_tohamy@art.suez.edu.eg \\ ahmed.algamal@art.suez.edu.eg
}

\section{Abstract}

This paper examines the prosodic features of the Pragmatic Marker (PM) you know in English spoken discourse produced by Egyptian speakers. The prosodic features examined in this study include initial and final pitch, duration and the type of tone associated with the PM you know. These features are identified by applying auditory perception and acoustic measurements to the PM you know in an English discourse produced spontaneously by male and female Egyptian speakers and one native speaker as an example of the typical native use. For the auditory measurement, a jury of five English language experts are consulted. For the acoustic measurement, you know is analyzed each time it occurs using a computer-aided method (PRAAT, Version 6.1.03). The results show that the PM you know is used to serve such pragmatic functions as signaling repairs, marking content, and providing common grounds between interlocutors. The results also prove that the PM you know is used with a level tone (about 10 times) by the Egyptian speakers. The female 
Egyptian speakers tend to have higher pitched PM you know at final position than their male counterparts. The PM you know tends to have the same duration in the cases of both male and female speakers.

Key words: pragmatic marker, you know, Egyptian English spoken corpus, perception, acoustic measurement.

\section{المستخلص باللغة العربية}

“you تعرض هذه الاراسة الملامح التطريزية للعلامة البرجماتية

know" الإنجليزية، حيث تشمل هذه الملامح بداية ونهاية النبر الصوتى، والمدة التى تستغرقها هذه العلامة ونمط التنغيم المرتبط بها حينما تستخدم. ولتحديد هذه الملامح بواسطة القياسات السمعية والأكوستية للعلامة البرجماتية you" و know" و الذكور. وقد تم تطبيق القياس السمعى لتكرار حدوث هذ العلامة البرجماتية بالاستعانة بمحكمين خبراء فى مجال اللغة الإنجليزية، والقياس الأكوستى بإستخدام برنامج الحاسوب برات (PRAAT). ولقد خلص الباحثان من نتائج بحثهما إلى استخدام الناطقين المصريين للعلامة البرجماتية you know بنمط تنغيمى مستوى ثابت (مايقرب لـ 10 مر ات). تميل الناطقات المصريات إلى رفع النبر الصوتى فى نهاية العلامة البرجماتية أكثر من الناطقين الذكور. تتساوى المدة التى تستغرقها العلامة البرجماتية عند كلا من الناطقين الإناث و الذكور. الكلمات المفتاحية: العلامة البرجماتية، you know، خطابات المصريين الثفهية باللغة الإنجليزية، الاستقبال السمعى، القياس الأكوستى. 


\section{Introduction}

Based on Kachru's classification (1985) of world Englishes, English is used as a foreign language in countries such as Egypt, and "Egyptian English" can thus be classified as belonging to the expanding circle, the third circle in which English is spreading as a foreign language in the fields of research, tourism, international affairs and transactions. It seems that little research has been done on the intonational and prosodic features of English Pragmatic Markers (henceforth PMs) when used by non-natives in general, and Egyptian speakers of English in particular. So, the purpose of this study is to unfold many of the prosodic features of Egyptian English in relation to PMs.

According to Redeker (2006), PMs are surface phenomena which mirror a speaker's mental processes that reflect what goes on in their mind. Aijmer (2013, p. 4) argues that PMs can emerge as "overt indicators" of ongoing metalinguistic activity in the speaker's mind. Thus, using a PM helps to organize discourse and make it more coherent. In addition, a PM typically occurs at transitions in the discourse where the hearer needs to be made aware that a new activity starts or that the speaker takes on a new role. 
Erman (1987, p.143) describes pragmatic expressions such as you know as "structures where there is a break in the syntactic structure." The function of you know lies mainly in delaying or taking time searching for the right words. In addition, according to Jucker and Smith (1998), the PM you know is a presentation marker. A presentation marker is used to modify and evaluate the speaker's own information. They further claim that strangers make use of a higher rate of reception markers, i.e. use of yeah, compared with friends, while friends employ presentation markers, i.e. you know, more frequently. Pragmatic Markers, according to Erman (2001, p.1340), can be viewed as "monitors" from three domains: textual/ideational, social/interpersonal, and metalinguistic. As social monitors, Müller (2005) makes clear that PMs have clearly interactional functions. They involve the audience by asking for confirmation of understanding or of a previous claim, and asking for agreement with a statement or reference. Thus, they can have a comprehension-securing function.

The distribution of the PM you know is also significant. According to Erman (1987) and Crystal (1988), when it occurs in the middle of the sentence, it functions as clarifying any misunderstanding of what has been previously 
said. It also alerts the conversation partner that what comes next is very important.

The auditory perception, handled within the framework of cognitive linguistics, is used in this study as a tool of analyzing the data obtained. Dorothy (2002) argues that perceiving intonation can be done by means of two main aspects: first, the human ability to perceive the physical properties of frequency, duration, and intensity, and second, the psychological response to various acoustic stimuli (p. 12). Although some previous psychophysical research has been able to isolate the individual elements of fundamental frequency, duration, and amplitude, and to determine listeners' abilities to perceive them, psychoacoustic research on suprasegmental features including pitch, length, and loudness, has suggested that listeners use a combination of these components in order to make optimal perceptual judgments (p.13). Cruttenden (1997) points out that perceptual experiments have shown that there are three perceptual features to be investigated: pitch, duration, and loudness.

The perceptual and acoustic measurements of the PMs used by the Egyptian speakers in this study reveal 
certain features necessary for comparing and contrasting the Egyptian's PMs with those of the native speakers of English. These features are known as prosodic. According to Wennerstrom (2001, p. 17), prosody includes a number of speech characteristics traditionally considered "suprasegmental" or separate from segmental phonology. Of these, the main aspects treated in this study include intonation (fall, rise, fall-rise, rise-fall or level tone), pitch (initial and final) and length (whether short or long in duration). In order to convey various types of meaning in spoken discourse, speakers tend to manipulate their pitch and associate particular tones with the PMs used.

\section{Research Problem}

The purpose of this study is to investigate the PM you know in spontaneous Egyptian English spoken discourse by using both auditory perception and acoustic measurements. The literature shows that PMs have often been studied from a discourse (e.g., Müller, 2005 and Redeker, 2006), or pragmatic (e.g., Erman, 2001 and Aijmer, 2013) perspective. Few are the studies that have covered prosodic aspects of PMs. Thus, this study focuses on the PM you know, which differs acoustically and perceptually when produced by natives and non-natives. 


\section{Questions of the study}

1- To what extent is the auditory perception measurement similar to/different from the instrumental/acoustic one in describing some prosodic features (initial and final pitch and duration) of the PM you know?

2- What are the pragmatic functions of the PM you know as elicited from the data?

3- To what extent is the use of the PM you know by the Male speakers similar to/different from the female speakers in their Egyptian English spoken discourse?

\section{Objective of the study}

This study investigates the prosodic features of the PM you know in spontaneous Egyptian English spoken discourse to find out whether or not it is similar to, or different from the same marker produced by native speakers in terms of auditory perception and acoustic measurements.

\section{Literature Review}

In the Oxford Online Dictionary, the PM you know is "used as an almost meaningless expression when the speaker is thinking what to say next". In a study conducted by 
Östman's (1981, p. 22) in which you know is approached from a politeness framework perspective, the PM you know is used when the speaker wants the hearer to cooperate and accept the content of the speaker's utterance without arguing. Since the hearer's opposition would be a threat to the speaker's face, you know thus works as a face-saving device. However, there is another way in which you know fulfills politeness functions. By using it, the speaker pretends shared knowledge, and this achieves intimacy.

The PM you know fulfils a number of pragmatic functions. Many linguists (e.g., Ostman, 1981; Schourup, 1985; Holmes, 1986; Erman, 1987; Erman, 1992 and Müller, 2005) recognize its major function as indicating lexical or content processing. Ostman's (1981) argues that there is a distinction between lexical search in which you know is being followed by a pause, and content search in which it is potentially preceded by a pause. However, Müller (2005) claims that pause is not a decisive element for such a distinction.

Schourup (1985, p. 103) claims that the use of you know as a pragmatic marker provides some kind of "common ground" between hearer and speaker. It also expresses uncertainty about this common ground. For instance, it may be used to make sure that the speaker's message has been 
conveyed and/or acknowledged, and that the hearer is familiar with what the speaker talks about. Besides, Holmes (1986, p. 11) points out that you know "is generally preceded by a pause or a verbal hesitation such as erm or er'. Erman $(1987 ; 1992)$ also views that the PM you know is accompanied by several hesitation markers, such as filled and/or unfilled pauses.

As pointed out by Müller (2005), The PM you know can be used to mark false start and repair. Erman (2001, p.1337) also shares the same view that you know functions as a 'textual monitor' in order to signal repair. She claims that you know occurs in places where the speaker stops in midstructure to make a restart. Similarly, Holmes (1986, p. 11) finds out that you know can indicate a false start, or, in other words, mark "a change of syntactic direction". This means that what follows the PM you know may be different from what precedes it. Thus, Holmes and Erman apparently talk about the same phenomenon, even though they use different terms.

Another less frequently used function of you know is marking approximation. Described by Stubble and Holmes (1995, p. 69) as a pragmatic device, you know functions as 
expressing uncertainty, or as they put it, the absence of "the linguistic precision of the message." Müller (2005, p. 164), in her study, concludes that you know is used to mark the lacking exactness.

In order to structure the contents of what the speaker says, the PM you know is used to introduce an explanation, which makes clear the message being said. According to Crystal (1988), when you know occurs in the middle of a sentence, it is often used to clarify or amplify the meaning of what one has just said. It warns the listener that the next words are particularly important. This claim supports that of Erman (1987, p. 114) who states that you know is used to "introduce a clarification of a previous statement" when it occurs within the sentence. Erman $(1986 ; 1987)$ claims that you know is used to introduce exemplifications.

\section{Pragmatic Markers and Prosody}

The meaning of a pragmatic marker depends on the context in which it is used. There is not a fixed meaning but a meaning potential for a PM. According to Noren and Linell (2007), the theory of meaning potential can cope with the meaning representation of lexical items which have no strictly delimited meanings but develop meanings in contexts. They further claim that "the linguistic resources 
provide language users with semantic resources to understand, say and mean specific things in particular usage events, and that this always involves an interplay with contextual factors" (p. 387).

Another important element that provides PMs with the contextual meanings they require is prosody. This goes in line with Trillo-Romero (2012, p. 121) who argues that "PMs appear with multiple intonation realizations and have a distinct prosodic entity", and this depends on their position in the tone unit, whether used at the beginning or at the end. He further claims that it is difficult for non-native speakers of English to use PMs due to their prosodic features, which affect the pragmatic meaning. He thus goes far to claim that the meaning of PMs is always assigned by prosody.

It is also important to shed light on pitch from an intonational perspective. Gussenhoven (2004) states that tone and intonation are two types of pitch variation. In addition, Ladefodged and Johnson (2011, p.254) define intonation as "variation in pitch". They further add that pitch level reveals nonlinguistic information about the speaker's personal characteristics and emotional state. From the pitch level, it is easy to determine whether the speaker is male or female, old 
or young, happy or sad, angry or calm. The most frequent intonation patterns in each speaker's utterances according to Roach (1993) are five basic types:

- Rising tone: the pitch of the voice rises over time [/]

- Falling tone: the pitch falls with time [ ]

- Fall-rise tone: the pitch falls and then rises [

- Rise-fall tone: the pitch rises and then falls [ $\wedge$ ]

- Level tone: no change in the pitch variation [- ]

\section{Method and procedures}

The study sample consists of linguistic data produced by Egyptian speakers of English. The spoken sample is a collection of spoken language data from interviews with intermediate to advanced female and male Egyptian speakers of English, and it includes (3888) words in which the pragmatic marker you know is used once by the native speaker and (19) times by the Egyptian speakers of English.

The reason why the acoustic measurement is used along with the auditory perception is that auditory perception is an impressionistic and personal measurement that needs to be acoustically verified by means of a computer-aided software tool (Praat). So, both auditory and acoustic analyses are performed in order to identify the pitch movements and uncover the prosodic features of the PM you know. In the 
auditory perception measurement, the pitch movement (i.e., high and low pitch) and duration of you know are described by inviting a jury consisting of five members to hear clipped utterances containing the PM you know 20 times and choose the most appropriate tone associated with the PM each time they hear it. Informants are to decide whether the tone of the PM you know is fall, rise, rise-fall, fall-rise, or level.

For conducting acoustic measurement, there are a number of dimensions involved. First, the type of tone associated with the PM is identified. Second, the function of the tone associated with the PM is determined. Third, the type of pitch whether low or high, initial or final is given. To do so, the sound files retrieved from the data of native and nonnative speakers are edited and clipped into individual files containing the PM you know. The instrumental analysis is done using a computer-aided method (PRAAT: Boersma and Weenink, 2019, Version 6.1.03).

\section{Analysis}

The Egyptian speakers of English in this study have used the PM you know to serve various pragmatic functions. You know, for instance, functions as signaling repairs, 
marking content or lexical search, and proving common ground between the interlocutors. These functions are made clear by means of the auditory perception and acoustic measurements.

First, the auditory perception of the PM you know attempted by the informants in this study shows various results. Based on the notion that auditory perception involves personal judgments and impressions, the results obtained shows a good deal of subjectivity over objectivity. The PM you know produced by the native speaker is auditorily perceived to have various tones (i.e., rise-fall, rising, fall-rise) by the informants, and when measured acoustically, it has a level tone. That is why the auditory perception is sometimes at odds with the acoustic measurement. However, in most cases of the Egyptian male and female speakers' production, the informants auditorily perceive the PM you know to have a level tone. This point of agreement suggests that the Egyptian speakers of English seem to stick to a certain tone, i.e., the level tone, which shows monotony and dullness.

Second, the acoustic measurement of the pitch level and duration of the PM you know is done using Praat (Version 6.1.03), a computer-aided method. Unlike the impressionistic information obtained from the informants concerning the type of tones associated with you know, the results of acoustic 
measurements show fairly precise information about both the pitch level and duration. The acoustic measurement shows that the primary tones, i.e., level, falling and rising are associated with the PM you know. However, the level tone occurs 10 times, the rising tone 7 times and the falling tone 3 times, as shown in Fig. 1. In this Figure, the 20 occurrences of the PM you know as produced by the native (once) and Egyptian speakers of English (19 times) are given from 1 20. Both the initial and final pitch for the PM you know are displayed; the initial pitch is in blue and the final pitch in red. An estimated type of tone based on the pitch movement/direction is also given for each occurrence of the PM you know. It is noted that the types of tone frequently associated the PM you know, as shown in the Figure, are level, rising and falling respectively. 


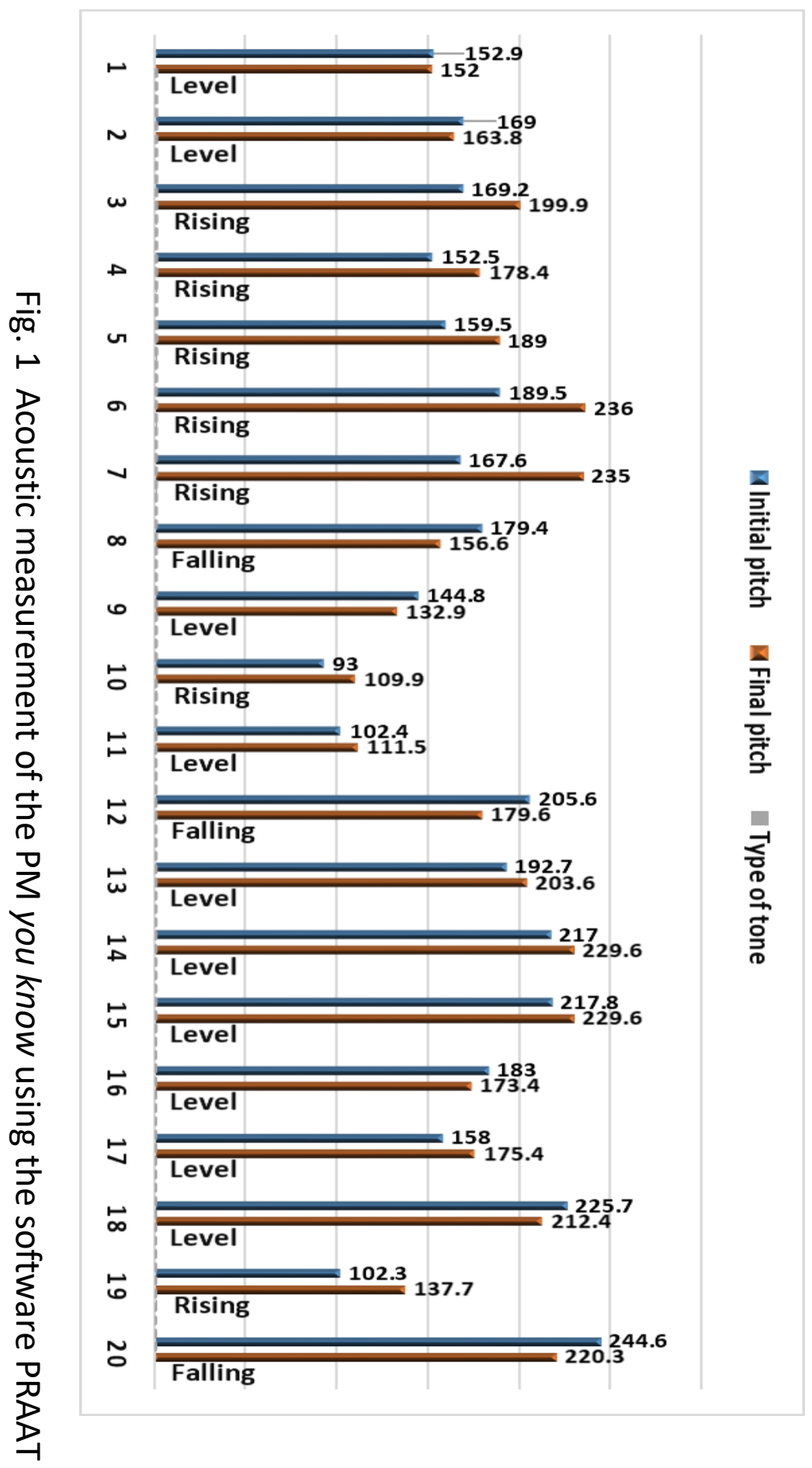


Given the gender differences in pitch range, Fox (2000, p.299) refers to the fact that female speakers tend to have a high pitch range than that of the male speakers. Most men typically range between $85-180 \mathrm{~Hz}$, and most women between $165-255 \mathrm{~Hz}$. However, To verify this, the initial and final pitch of the markers have been analyzed as produced by male and female speakers. The mean value for the initial pitch of the PM you know by the female Egyptian speakers is $187.76 \mathrm{~Hz}$, and that of the male speakers $152.70 \mathrm{~Hz}$, as shown in Fig.2.

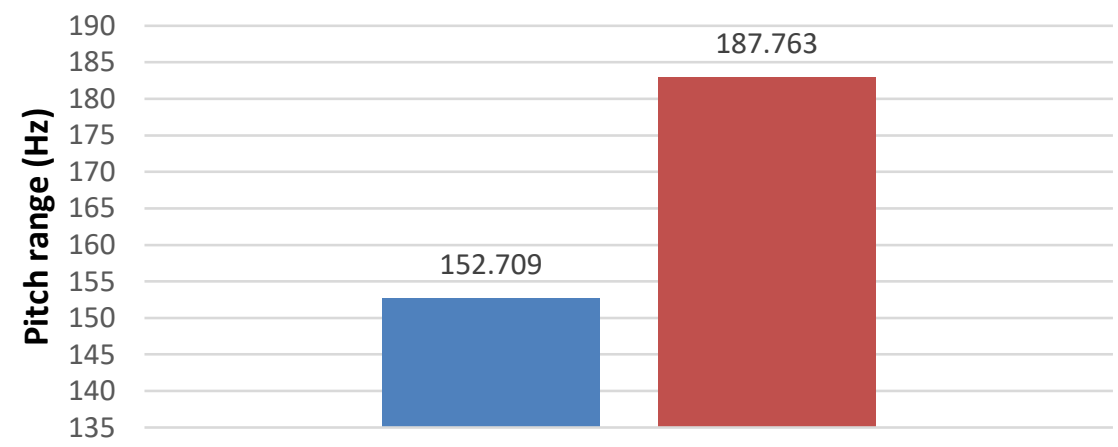

Pitch Meân Values

घ Male Speakers' Initial Pitch घ Female Speakers' Initial Pitch

Fig. 2 Mean Initial pitch of the PM you know 
The mean final pitch for the PM you know as produced by the female Egyptian speakers is $192.66 \mathrm{~Hz}$ and by the male speakers $169.54 \mathrm{~Hz}$, as shown in Fig.3.

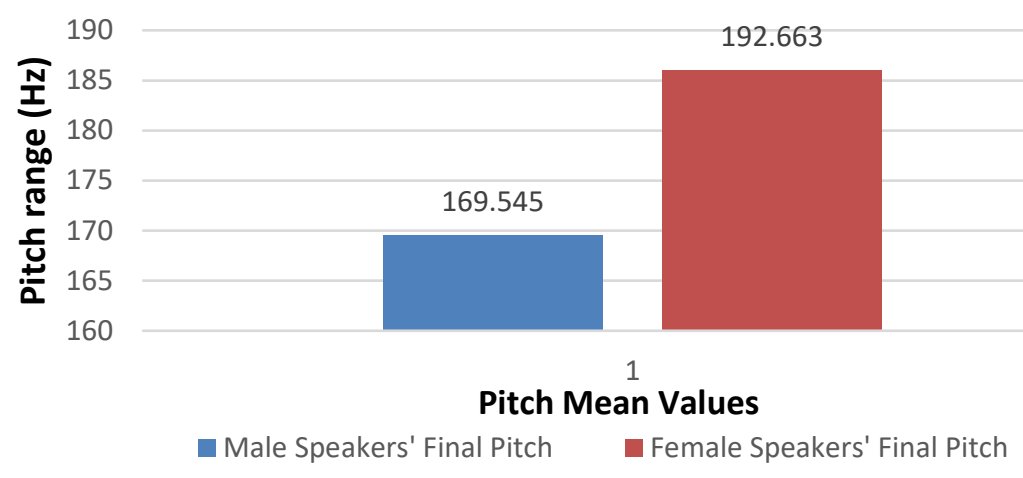

Fig.3 Mean Final Pitch of the PM you know

Based on the mean values of the initial and final pitch of the PM you know, there is a marked difference in producing this PM by both the male and female Egyptian speakers of English. First, the pitch range in the case of female speakers is higher than that of the male speakers. Second, the final pitch in the case of female speakers is comparatively higher than that of the male speakers. It is very significant in statistical terms, and this might indicate that the female Egyptian speakers are not perceived as assertive as the male Egyptian speakers.

The differences in the initial and final pitch values in the use of the PM by the Egyptian speakers of English 
indicate that the various types of primary tones can be distinguished. Thus, the variation between initial and final pitch measures in both male and female Egyptian speakers is different (mean value for male speakers $=161.12 \mathrm{~Hz}$; mean value for female speakers $=190.21 \mathrm{~Hz}$ ), with significant statistical differences. This means that certain tone contours (i.e., level, rising and falling) associated with the PM you know can be audibly and acoustically differentiated as shown above.

Another prosodic element that features the use of the PM you know by male and female Egyptian speakers is that the duration is practically the same. It is worth mentioning that the duration is not auditorily perceived, but acoustically measured. So, based on the instrumental measurement, the mean duration of you know in the case of male speakers is $0.279 \mathrm{~ms}$ and in that of the female speakers 0.283ms. In Fig. 4, the duration of the PM you know as produced by male and female speakers is shown. The frequency and time in milliseconds are displayed for each occurrence of you know. 


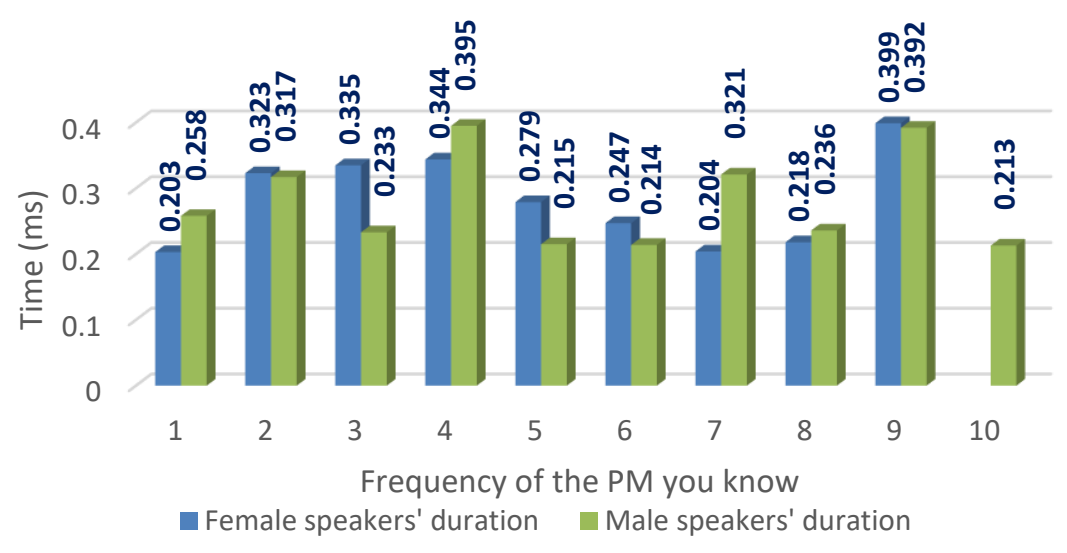

Fig. 4 Duration of the PM you know in male and female Egyptian speaker of English

The overall perception of the PM you know for both male and female Egyptian speakers shows that you know has the same duration in both cases, which indicates in general terms, the use of PM you know may result in being pragmatically unclear (Trillo \& Newell, 2012) when compared with the native speaker's duration $(0.319 \mathrm{~ms})$ in this study. In addition, the PM you know as produced by the female Egyptian speakers is used with a low pitch level in comparison with the female native speaker, (i.e., initial pitch is $244.6 \mathrm{~Hz}$ and final pitch $220.3 \mathrm{~Hz}$ ). However, the final pitch in the case of female Egyptian speakers, (i.e., mean value $192.21 \mathrm{~Hz}$ ) is relatively higher than that of the male Egyptian speakers, (i.e., mean value $169.54 \mathrm{~Hz})$. 


\section{Discussion}

When comparing the results of both the auditory and acoustic measurements, it is found out that the auditory perception may provide initial, non-confirmed information about the pitch movement and type of tones associated with the PM you know. The acoustic measurement, in contrast, is used to achieve credibility and to confirm the initial information obtained from the auditory analysis. In this study, both the auditory and acoustic measurements confirm that the prevailing tones associated with the PM you know are the level, rising and falling tones respectively.

The auditory perception measurement of the PM you know by the English language experts indicates that the tone associated with you know each time is different, even their impressions vary widely the same time the PM you know is used. While the tone associated with you know most of the time is acoustically level, the jury members assign different types of tones. This means that perception is influenced by external factors including background noise, hearer's attitude toward the overall meaning of the phrase, etc. Accordingly, human perception may vary from one person to another based on those external factors. 
There are two prosodic elements that contribute to the speaker's assertiveness in producing the PM, namely high initial pitch and short duration. In this study, female Egyptian speakers tend to have a high pitch level at final positions of the PM you know compared to male Egyptian speakers. This is possibly the reason why the female Egyptian speakers are not perceived as assertive as the male Egyptian speakers of English.

When it comes to compare the data of the female Egyptian speakers with that of the native speaker (who is also a female speaker), it is found out that both produce the PM you know with a high pitch level compared to male speakers. This may enhance the common belief that women tend to have high pitch level than men do. However, concerning the duration, which is acoustically measured, the female native speaker tends to have longer duration than both male and female Egyptian speakers do. This indicates the reason why native speakers may sound non-affirmative and tentative with the PMs.

\section{Conclusions}

The purpose of this study is to investigate the use of the PM you know as produced by Egyptian speakers of English. To achieve this goal data are collected and analyzed 
in two phases of analysis: the auditory perception and acoustic measurements. The auditory perception of the PM you know, which occurs about 20 times (once by the native and 19 times by the Egyptian speakers) is carried out by asking a jury of English language experts to decide the type of tone with the PM each time it occurs. The acoustic measurement is done by Praat (Version 6.1.03), a computeraided method, which provides accurate analyses of the sound data inputted. In this stage, the audio files are clipped and then fed into the software program.

The results of this study show that the PM you know is used with a level tone (about 10 times) by the Egyptian speakers of English. This might indicate the speakers' insufficient exposure to spoken English, and thus inability to use the right tone. In addition, the female Egyptian speakers as well as the female native speaker tend to have higher pitched PM you know at final position than their male counterparts. Thus, female Egyptian speakers are not perceived as assertive as the male Egyptian speakers of English. The PM you know tends to have the same duration in the cases of both male and female speakers. However, the native speaker in this study tends to have a relatively longer 
duration when compared to both male and female Egyptian speakers. This may indicate that when the Egyptian speakers of English use the PM you know, they seem to be pragmatically unclear compared with the typical native use (i.e., long duration of you know) in this study.

\section{References}

Aijmer, K. (2013). Understanding Pragmatic Markers: A Variational Pragmatic Approach. Edinburgh: Edinburgh University Press.

Boersma, P. \& Weenink, D. (2019). Praat: Doing phonetics by computer [Computer program]. Version 6.1.03, Available at: http://www.praat.org/

Cruttenden, A. (1997). Intonation. Cambridge: Cambridge University Press.

Crystal, D. (1988). “Another look at, well, you know...” English Today, $13,47-49$.

Dorothy, C. (2002). Discourse Intonation L2. From theory and research to practice. Amsterdam-Philadelphia: John Benjamins Publishing Company.

Erman, B. (2001). "Pragmatic markers revisited with a focus on you know in adult and adolescent talk". Journal of Pragmatics, 33, 1337-1359.

Erman, B. (1992). "Female and male usage of pragmatic expressions in same-sex and mixed sex interaction". Language Variation and Change, 4, 217-234.

Erman, B. (1987). Pragmatic Expressions in English. Stockholm: Almqvist \&Wiksell.

Fox, A. (2000). Prosodic Features and Prosodic Structure: The Phonology of Suprasegmentals. Oxford: Oxford University Press 
Gussenhoven, C. (2004). The phonology of tone and intonation. Cambridge: Cambridge University Press.

Holmes, J. (1986). “Functions of you know in women's and men's speech". Language in Society, 15, 1-22.

Jucker, H. \& Smith, W. (1998). “And people just you know like 'wow': Discourse markers as negotiating strategies". In A. H. Jucker and Y. Ziv (Eds.), Discourse Markers: Description and Theory (pp. 171-202). Amsterdam: John Benjamins.

Kachru, Y. (1985). Discourse analysis, non-native Englishes and second language acquisition research. World Englishes, 4(2), 223-232.

Ladefodged, P. \& Johnson, K. (2011). A Course in Phonetics $\left(6^{\text {th }}\right.$ ed.). Boston, MA: Wordsworth.

Müller, S. (2005). Discourse Markers in Native and Non-Native English Discourse. Amsterdam: John Benjamins.

Norén, K., \& Linell, P. (2007). Meaning potentials and the interaction between lexis and contexts: An empirical substantiation. Pragmatics, 17(3), 387-416.

OED (n.d.) You know in Oxford English Dictionary. Retrieved September 2019, from https://www.oxfordlearnersdictionaries.com/definition/english/ know_1\#know_idmg_35

Östman, J. O. (1981). You know: A Discourse-Functional Approach [Vol. II:7: Pragmatics \& Beyond]. Amsterdam: John Benjamins.

Redeker, G. (2006). 'Discourse markers as attentional cues at discourse transitions'. In K. Fischer (ed.), Approaches to Discourse Particles. Amsterdam: Elsevier. 339-58.

Roach, P. (1993). English Phonetics and Phonology. Cambridge: Cambridge University Press. 
Schourup, L. (1985). Common Discourse Particles in English Conversation. New York: Garland.

Trillo, J. R., \& Newell, J. (2012). Prosody and feedback in native and non-native speakers of English. In Pragmatics and prosody in English language teaching (pp. 117-131). Springer, Dordrecht.

Wennerstrom, A. (2001). The music of everyday speech: Prosody and discourse analysis. Oxford: Oxford University Press. 